\title{
Reaching out in a climate of negativity: perceptions and persistence among Muslim sources engaging with news media
}

\author{
Michael B. Munnik ${ }^{1}$
}

Published online: 17 March 2018

(C) The Author(s) 2018

\begin{abstract}
The conceptions sources have of journalists influence whether and in what ways those sources engage with the news media. In this paper, I consider the contribution of Muslim sources to news in a context of perceived negativity. Scholarship on the content of British news stories about Muslims has found a consistently negative tone; my study examines the impressions of sources as co-producers of that content. My data come from qualitative fieldwork conducted in Glasgow, Scotland, studying relationships between journalists and Muslim sources through a combination of methods, with an emphasis on interviews. In these interviews, sources articulated an overwhelmingly negative conception of journalists and news organisations. I consider different constructions of negativity and what they suggest about how participants perceive the media, and I problematise the minority instances of positive conceptions. Finally, I evaluate why sources who identify as Muslim would bother participating in media production, given this perception of negativity. This discussion is informed by Couldry's concept of 'media meta-capital' (Couldry 2003), which a macro-level power that imposes other fields of public life, and Schlesinger's attentiveness to source strategies (Schlesinger 1990), a form of agency at the micro-level. This case study suggests that, whatever sources think of media coverage, their choice to contribute to its production is conditioned by strategic considerations, revealing development in the media's relations with Muslims in Britain.
\end{abstract}

Keywords Media $\cdot$ Muslims $\cdot$ Journalist-source relations $\cdot$ Representation $\cdot$ Scotland Muslims in Britain

Michael B. Munnik

munnikm@ cardiff.ac.uk

1 Centre for the Study of Islam in the UK, School of History, Archaeology and Religion, John Percival Building, Cardiff University, Colum Drive, Cardiff CF10 3EU, UK 
No one needs to talk to the media. Though conventions may exist that elected representatives, spokespeople for state agencies, or academics with expertise ought to answer journalists' questions, there is no statutory requirement, and an excuse can always be made. Politicians in an election campaign make calculated decisions on the costs and benefits of appearing on news programmes and televised debates; once in office, they can withhold access to certain organisations in favour of others. They risk bad publicity and public shame, but these are normative levers, not regulative ones. This freedom to deny media access descends the social hierarchy to ordinary citizens, though they may not be aware of it (MediaWise n.d.). Nonetheless, official representatives feel social pressure to speak, and so can ordinary citizens. Muslims, as a newsworthy population in Western contexts, are frequently made answerable for criminal and terrorist acts committed by other followers of the religion. ${ }^{1}$ They may feel compelled to speak in the news to contribute to the construction and adjustment of narratives about their religion and social cohort. Alternately, they may choose to participate in the news media as an act of citizenship. There are push and pull factors in the decision to speak to journalists, which I explore below.

First, we must recognise that media narratives about Muslims are often negative. This can lead to a disinclination to speak: if you believe the media never say anything good about you and your fellows, why bother speaking at all? The categorical negativity of the media can take on exaggerated proportions. Osama Saeed ${ }^{2}-$ once $^{2}$ an activist in Glasgow, Scotland and, at the time of our interview, the media relations head of Al Jazeera in Doha - identified this distorted portrait: '[U]ltimately, the Muslim community - and I'm going to make a monolithical, grand, sweeping statement, here they have a very [...] monolithic view of media, in the same way that sometimes the media have a monolithic view of Muslims, which is that the media are all bad, and they are all out to get us.' As the quotation shows, Saeed was aware of the essentialising nature of his comment even as he offered it, and he strategically connected it to the prevailing view of how Muslims appear in the media, so that misrepresentations are made by both parties in both directions.

In this article, I briefly outline the scholarly literature, which largely accords with 'the monolithic view' that Saeed says the media sometimes have of Muslims. I then explore the details of his primary 'monolithical, grand, sweeping statement': what do Muslims think of the media? Specifically, what do Muslims who are active in media relations think of the media? This is important because, in spite of the near-uniform assessment that coverage is negative, with often far stronger words being used, these Muslims persist in adopting the role of source. What strategic advantage do they see in participating in a media that they feel is out to get them? Having established the character of their perceptions of the media, I examine the beneficiaries of their relationships with journalists. I identify inward orientations - benefits to the individual and to the community of Muslims with which they identify - as well as external orientations to journalists and to society as a whole. These findings contribute to our

\footnotetext{
1 Though scholars have noted that Muslims tend more to be spoken about than spoken to (Alderman and Mast 2017; Richardson 2006).

${ }^{2}$ Participants in my study were offered the choice to disclose their identity or be anonymised. Many occupy public roles, and properly obscuring their identities would be difficult. Most consented to this disclosure. Anonymised sources are introduced as such in the text, where this is relevant.
} 
understanding of the character of the news media as a social institution as well as the influence disadvantaged groups have on its course and conduct.

\section{The media: All bad and out to get Muslims?}

The familiar complaint that the media vilify Muslims can be traced back to Edward Said. His encounters with primarily US news media following both the publication of his book Orientalism and the Islamic revolution in Iran informed his polemic work Covering Islam, in which he criticised the reporting and identified a representation common to both journalistic and political discourses at the time, that 'Islam is a threat to Western civilization.' (Said 1997: 144) His assessment has proved as influential as it is controversial. 'Islamophobia' is not a word Said employed in his original analysis, though it captures the sentiments he observed. The Runnymede Trust's report Islamophobia: A Challenge for Us All (Commission on British Muslims and Islamophobia 1997), which popularised the term, contrasted 'open' and 'closed' views of Islam, with one chapter dedicated to the British media's role as a carrier of closed or Islamophobic views.

Scrutiny of these views has dominated periodic studies of British news content. The research for Elizabeth Poole's book Reporting Islam ran contemporary to the Runnymede Trust's investigation, and she called the media 'an instrument of public ideology [which] demonizes Islam' (Poole 2002: 17). Examining a more limited sample of broadsheet newspapers at a similar time, John Richardson (2004) found that media discourses produced and reproduced harmful rhetoric about Muslims. A team from Cardiff University studied the post-9/11 period in the British press and found, not surprisingly, that coverage had risen significantly after 2001 and had stayed consistently high since, and the focus was on 'negative or problematic contexts' (Moore et al. 2008: 3). Though the report's authors attempted to distance themselves from a simple 'positive/negative' binary judgement, they found judgements in news coverage that were 'unfavourable' four times as often as they were 'favourable', as well as common discourses that 'associate Islam/Muslims with threats, problems or in opposition to dominant British values.' (Moore et al. 2008: $8,13,15)$ Finally, and authoritatively, a team of corpus linguists from Lancashire (Baker et al. 2013) led a dense study of the language the British press used to describe Muslims and interpreted what that language indicated about attitudes: they found that Muslims were frequently associated with conflict and constructed as a monolithic, homogeneous bloc. These content studies confirm the baseline contention that Muslims are reported on negatively in the press.

Not all content studies share this conclusion. Erik Bleich and colleagues (Bleich et al. 2015) studied headlines in the British press and intentionally evaluated their content on a positive or negative bearing. Although the authors expected to corroborate previous studies, they found a slight majority for positive rather than negative representations. They temper this by noting that the newspaper with the highest circulation in their study skewed much more to the negative than that with the lowest circulation; therefore, although the weight of their sample inclines to positive tones, the actual reach of these headlines in terms of readers favours the negative (Bleich et al. 2015: 954). Moreover, their sample compared headlines about Muslims with those concerning Jews and Christians, and the Muslim set featured a generally more negative tone. 
Some scholars examine the issue by considering the impressions left on readers. For Rusi Jaspal and Marco Cinnirella (2010: 306), writing from a linguistic and social psychological perspective, these negative representations in the media 'have a dual function': in the first instance, they enhance 'the distinctiveness and self-esteem principles of identity among the readership,' a readership which, they note, is assumed to be white, non-Asian, and non-Muslim; secondly, the threats constructed in these media representations 'may jeapordise the continuity principle of identity'. Thus, reports about the presence of Muslims in Britain, with their distinctive claims or, in some news reports, their association with terrorism and extremism, imply a threat to a continuing British identity that is ethnically white and culturally Christian. Laurens de Rooij (2017) looks at this issue from the other angle, in which 'British civil religion', composed of a fusion of Christianity and notional British values, becomes the positive standard in media narratives against which other expressions of identification are judged. Whether white British Christian culture is threatened by the presence of Muslims or lionised as a superior and preferable alternative to Islam, these scholars suggest that such narratives shape and are shaped by negative news coverage of Muslims.

\section{The importance of sources}

Scholars have used sophisticated theoretical and technological tools to inform their conclusions that the news media represent Muslims negatively. Lay understandings emerge without the benefit of such rigorous analysis but can arrive at the same conclusions. Readers of social research on Muslims in Britain will not be surprised by this: within focus groups or a schedule of interviews, researchers often ask about media representations, and similar themes of negativity and vilification prevail (Ali 2008; Kabir 2010; Samad 1998). Salman Al-Azami (2016: 130-133) composed focus groups according to religion for his study of audience response to media representations of religion, and the Muslim audiences rejected the portrayals of Islam that he had selected for discussion. My sample is distinguished by the fact that the participants are sources, meaning they are in active relationships with journalists, though as we shall see, such relationships do not necessarily lead to a more favourable attitude towards journalists.

Sources are a valuable population to study because of their integral role in the production of news. Jeremy Tunstall (1971) identified sources as a group to which journalists are beholden in their work. Herbert Gans (1980: 281) deemed sources 'of prime significance' for journalists in deciding what news is. Gans encouraged more scholarship on the strategies sources employ in their relations with journalists, and scholars in different national contexts and specialist subjects have taken up the charge (see e.g. Carlson 2009; Ericson et al. 1989; Manning 2001; Miller et al. 1998; Schlesinger 1990). Scholars often sort sources into categories of official and unofficial status, suggesting a journalistic preference for official sources (Ericson et al. 1989: 34). Given conceptions of Muslim subaltern counterpublics (Willemse and Bergh 2016), one could ask whether Muslims attain the 'official' status required to satisfy this preference. However, Muslims in Britain occupy a variety of roles on the spectrum of officialdom, and they marshal their available capital in different ways to differing results in their relations with the news media (Munnik 2017a). Islam is a newsworthy 
story for the British media, and what Muslim sources think of journalists, journalism, and news coverage matters.

What follows is largely based on impressions. Between August 2012 and March 2014, I carried out fieldwork in Glasgow, Scotland. Glasgow is a unique news ecosystem, housing headquarters for both local and Scottish-national news organisations as well as the Scottish headquarters for UK-national organisations. Scotland offers a distinctive model of relations between Muslim communities and the population (Bonino 2016; Hopkins 2017; Hussain and Miller 2006; Meer 2015), though this has not been studied in relation to media representation or framing. My research examined not the content of Scottish reporting on Muslims but its production. Alongside observation and documentary analysis, I interviewed 30 participants, 12 of whom I classify as 'journalists' and 18 of whom I classify as 'sources'. For the purposes of this paper, my source sample increases to 19, including one journalist who identifies as Muslim; she is included to the extent that she speaks of attitudes among Muslims in Glasgow to journalists. Further details of my source sample are available elsewhere (Munnik 2017b).

Except in a few circumstances, the sources in my sample do not do journalism. They relate to the product of journalism as a representation of them, their organisation, or the religion with which they identify. They relate to the production of journalism through discrete encounters - points of contact in the midst of their daily lives. The impressions detailed here, therefore, are not always drawn from the most knowledgeable position, and we should think of them as revealing more about news sources than about journalists. This does not mean they are valueless as commentary on the news: as we have seen above, scholars have conducted independent analyses of news content concerning Muslims and come to similar conclusions. The impressions of those in my sample enrich the findings of content studies by revealing the impact of negativity on social interactions.

\section{Perceptions of Muslim sources}

My data on the perceptions of Muslim sources begin with their conceptions of the media. Sources frequently discussed 'journalists' (75 references in transcript) in general rather than specific journalists (28 references), and more often than that 'the media' (91 references) as a catch-all term. Often, those who had been more or less absorbed by news organisations or were in sustained, frequent contact were the ones who referred to specific journalists. If others made distinctions among the media, it was largely at the level of the organisation or the format: how the broadsheet Herald or BBC Scotland covers Muslims, or differences between tabloids and broadsheets. Although I prompted as often as possible for responses about Glasgow and Scottish-national media, participants often spoke of UK or global media. I divide comments concerning participants' attitude to the media into two main categories: substantive and functionalist. Substantive responses have to do with what the media or journalists are or qualities of their coverage, and functionalist responses concern what journalists and the media do - how they interact with Muslims. For this paper, I focus exclusively on substantive responses.

Attitudes to journalists and the media ranged from positive to negative, and a participant could express both positive and negative attitudes. Negative ones were far more frequent. Of all the words used to describe coverage, 'negative' or 'negativity' was the most numerous, and below, I examine a long list of words or phrases participants 
used in our interviews that are negative in tone. In describing the negativity of news coverage, several participants also said journalists 'rarely' or 'never' reported positive stories about Muslims. That, however, is an extreme rhetorical statement, and such claims would be difficult to substantiate in a measuring exercise. It is not my intention to verify such statements, though, after examining the dimensions of negative responses, I will briefly discuss positive responses concerning the media to balance the sample.

\section{Negative characterisations}

Ten participants used a variation on the word 'negative' to characterise directly journalists and journalism. Further, seven participants (with one also among the ten just mentioned, so there is overlap) said 'the community' believed that the media were against Muslims. One participant, whilst not using the word itself, gave a general impression of negative coverage of and engagement with Muslims. In total, 17 out of 19 participants depicted the media as negative towards Muslims.

The first expression of this characterisation was typically the opinion of my interviewee, as for example Fariha Thomas described 'pretty negative stuff that got massively worse after $9 / 11$, but even before that - just all these misportrayals.' Participants using the second expression distanced themselves from the opinion: it was something 'Muslims' or 'the community' felt. This is exemplified in Saeed's quotation from my introduciton, in which he speaks on behalf of other Muslims. Participants employing the second expression may have been portraying a kind of sophistication - an attempt to demonstrate their personal awareness of media processes and conventions, which might account for some of the 'bad news', whilst still articulating a view that demonstrated corporate solidary, suggesting coverage was negative and, by implication, problematic.

Only two participants of the 19 discussed in this paper did not characterise journalists or the media as negative. One, David Eyre, worked as a journalist for most of his career, and he does not identify as Muslim. He is included in the sample because of media training work that he had done with several groups, including AMINA-Muslim Women's Resource Centre (hereafter Amina), in the Govanhill and Pollokshields neighbourhoods of Glasgow. Eyre did not venture to portray the attitude of Glasgow Muslims to journalists. The other, Samina Ansari, was the development officer for Amina and the head of a campaign concerning public perceptions of Muslim women in Scotland that generated a high degree of media coverage. Ansari had a far more equivocal view of the media than other source participants, which was consonant with her manner of speech in talking about other people generally. She avoided stereotypes, and when she was critical of an individual or institution, she often followed the critique with a consideration of why this person might have said this or done that: "I'm just really conscious of how ... journalists will just jump on something [harmful] to get a good story. I'm sure it's really competitive for them as well, and they've got tight deadlines and things like that." I interpret this as partly due to her professional work, which is in counselling and community support, requiring a degree of diplomacy. I also attribute it to her rigorous positioning of herself as an acceptable Scottish citizen. She did not want to be seen to complain, to 'play the minority card' to make exceptional demands on society (cf. Meer 2012). Finally, I understand it as an attempt to be 
morally exemplary in a religious sense - to do what God asks her and not to be judgemental or critical of others. Ansari presents a special and interesting case, positioning herself as not being broadly critical for professional, political-social, and theological reasons.

Whilst Ansari did not describe the media as negative, she used the term 'agenda' twice in our interview. Agenda is among the words I class as being negative in tone, extending and informing the basic characterisation of negative. Four participants used the term, twice softening it as 'a wee bit of an agenda' and twice describing it as the government's agenda, by which they meant Westminster's foreign policy orientations. Three participants used a variation on stereotype and two a variation on bias. I counted 14 other words or phrases of this type which were used by only a single participant: commercially driven, essentialising, inaccurate, irresponsible, lacking a human element, not interested, offensive, propaganda, provocative, unrepresentative of the community, sensationalism, simplistic, sinister, and vicious.

We can distinguish this collection through terminological nuance. Agenda suggests the media are an actor in social processes, desiring a particular outcome. With bias and propaganda, this suggestion is softened, so that the media become an agent of other actors, complicit in social processes and influential without necessarily taking a position of their own. Hanzala Malik, a Member of Scottish Parliament, said, 'the BBC is now going down the route of basically being run by the government and our government's agenda. Which means they're no longer partial.' Given that two of the four references to agenda are tied to the state agenda, the three terms gathered here are related.

Five of the terms - essentialising, inaccurate, simplistic, stereotype, and unrepresentative of the community - concern a faulty understanding of Islam on the part of journalists. Arifa Farooq, a journalist herself, called coverage of men arrested for sexual offenses against underage girls 'so simplistic that it totally gives the wrong impression completely.' Of these terms, inaccurate may work in opposite directions to the other four: the former confronts a core value of Western journalism (Shapiro et al. 2013), so that journalists should be keen to uphold accuracy; whereas the latter conflict with institutional constraints, such as brevity. Accommodating these complaints can present further, profession-oriented challenges for journalists. These terms concern the specialist knowledge of the practitioner pitted against the generalised knowledge of the journalist, and as Mark Silk (1998: xi) puts it at the beginning of his discussion on US news coverage of religion, 'Anyone who knows something about anything is likely to be unhappy with the way it is covered in the news media.' This should not be read as an endorsement of complacency, but it illustrates that some at least of the negativity Muslim sources perceive in the news may be shared with other source communities.

Five more terms aggregate around news values and questions of process. Three can be further sorted as reporting values: irresponsible, lacking a human element, and sensationalism. These concern the content and the expression of news reports. As Robina Khan, a volunteer with Amina, put it, 'I think it's irresponsible journalism and irresponsible media when they start to use stereotypical words or terminology which is slightly biased...' Meanwhile, commercially driven and not interested are business values, relating to the operation of the news organisation. When Muslims make such a small proportion of the population and, as journalists in my study intimated, an even smaller proportion of the news audience, it is easy to ignore stories about Muslims in favour of topics and narratives that 'sell'. 
The final subset of terms sits at the extreme end of the characterisation of news as negative. Offensive, provocative, sinister, and vicious suggest outright hostility on the part of the media. Salah Beltagui, a trustee with the Muslim Council of Scotland, said 'some articles are vicious: somebody just wants to have a go at Muslims.' He talked of tabloid journalists calling him for comment on what he considered spurious stories - as he put it, 'laying a trap for me.' We can connect these terms with the idea of Islamophobia, which is not exclusively germane to the news media but which is often propagated and sometimes incubated by the news (Commission on British Muslims and Islamophobia 1997: chapter 4). In the original Runnymede Trust report, the authors use 'hostility' in their initial definition of Islamophobia (Commission on British Muslims and Islamophobia 1997: 4). With the contested term as a central focus, Nasar Meer and Tariq Modood (2009) found evidence of this hostility - sometimes openly celebrated among some prominent UK journalists. With a variety of foci, including the media as an actor or agent, faulty understanding of Islam, news values, and hostility, the weight of the attitudes of Muslims in Glasgow to the media is negative.

\section{Positive characterisations}

Nonetheless, participants did have some positive responses. One said journalists were 'okay' when a story was 'just factual.' Factual reporting here was distinct from opinion, which the participant, a volunteer with Amina, characterised as irresponsible, as discussed above. When I probed for examples, she mentioned exceptional use of the word 'fundamentalist': 'Why is it that Christian people are pious, and Jews are orthodox, but Muslims are fundamentalists if they want to...?' Her answer trailed off, suggesting that she was retreating from the positive assessment of coverage that her answer initially indicated.

More frequent positive characterisations concerned improvement and difference. Four participants suggested media coverage had improved or was improving since 9/11. Three of the four gave the example of reporting on the 2007 attack on Glasgow Airport as an illustration of better coverage, a more nuanced representation of Muslims, and an effort by some journalists not to resort to narratives of Islamic terrorism or Otherness. A fifth participant was ambivalent on the subject of improvement: she identified a greater interest in Muslims and Muslim stories, but she was unsure whether she considered the resulting coverage an improvement. Yet another participant, a politician, was emphatic that coverage had not improved since 9/11; our discussion hinged more on international coverage of conflicts in Egypt, Libya, Syria, and Palestine than local affairs.

The other typical positive response was that reporting on Muslims was different in Scotland as compared with the rest of the UK. This connects to broader statements from many of my participants outwith discussions of the media, suggesting that Scotland has a more receptive attitude to minorities as compared with the racialisation of politics elsewhere in Britain (Miles and Dunlop 1986). The four participants who made this statement in the context of media coverage were or had been politicians. Three of the four were also among those who suggested coverage had improved or was improving, which may indicate a relationship between the two attitudes. It may also indicate a limit on the scope of that improvement: the Scottish media have improved whereas the British media have not. 
My interpretation is that suggestions of both improvement and difference presuppose a consistent and coherent standard of what news coverage is and ought to be in Scotland and in Britain as a whole, none of which I would grant my participants. These comments, rather, indicate a disposition among participants. For political participants, there may be an advantage to speaking well of Scotland and less critically of journalists, who cover and therefore publicise the activity of politicians. However, they made these comments during interviews with an academic researcher whose findings, whilst public, are not widespread. Moreover, one politician participant did not suggest any signs of improvement or difference. It is likely that these conclusions are inspired by the participants' interest in public life, which includes the media, and their subsequently more granular appreciation of media practices.

We have established here that impressions of Muslim news sources concerning journalists, journalism, and news organisations are overwhelmingly though not exclusively negative. We have discussed some of the ways that this happens: direct statements about negativity, second-order ones that are attributed to 'some people' who are Muslim, and vague statements of general or structural negativity. We have a corpus of words and phrases that extend our understanding of these attitudes. Finally, it is important to remember that these are not necessarily accurate statements about news coverage: they are impressions from non-journalists. Because those in my sample engage with the media, their comments are worth analysing to help us think through the conditions of the production of news in Britain about Muslims.

\section{Persistence of Muslim sources}

In spite of this climate of negativity, Muslim sources continue to engage with journalists. All of the source participants in my study were active: they had spoken with journalists, been quoted in the news, or given reporters background information for their stories. We can exaggerate the good will that this persistent engagement suggests. If a source chooses not to answer the phone, this does not mean he or his organisation will be exempt from coverage. Journalists may write about them anyway, and the source has less control because he did not contribute a version of events by speaking. Talking, either on or off the record, gives the source a modicum of control over his representation in the news. Talking with journalists may also be a defensive manoeuvre. By hearing the journalist's questions, a source learns what the angle of the story might be, so she has time to prepare herself for any negative consequences.

For Muslims in Britain, the stakes are high: those identified with the religion experience a level of scrutiny exceptional even by the standards of a news media that generally seeks bad news (Baker et al. 2013), so engaging with journalists can become a form of community defence. Daniel DehHanas and Zacharias Pieri 2011 offer an example of a Muslim community overtaken by media and public debates. The Tablighi Jama'at proposed to build a large mosque in East London shortly after the 2005 announcement of London's successful Olympics bid and the subsequent terrorist bombings on the city's transit system. As the authors show, neither the group's silence nor its attempt to reframe the project and, therefore, the terms of the debate helped in the face of what they call a 'mega-event' that blocked its building plans (DeHanas and 
Pieri 2011: 801). This example illustrates both symbolic power of the media at the structural level and strategic actions to control events at the level of individual actors.

The media comprise a field with symbolic power. Issues and people are known through the 'selective and creative' choices of media producers (Thompson 1988: 364). Manuel Castells (1997: 316) calls media 'the space of politics', and though that designation does not give media determining power over the outcome of politics, it conditions the way political activity is conducted. For Nick Couldry, following the critical principles Pierre Bourdieu theorised for society in general and the media in specific, this symbolic power interposes on other fields 'by legitimating certain categories with not just cognitive but also social significance.' (Couldry 2003: 665) This is different from what is commonly understood as media effects, whereby the messages audiences consume in the media condition their thoughts or behaviour. Rather, it is the media setting the terms by which actors in other fields succeed or fail: meta-capital, Couldry notes, 'introduces the possibility that definitions of prestige within specific fields may be determined by influences outside those fields' (Couldry 2003: 667).

Media meta-capital, as its name suggests, is a macro-level theory for resources the media possess. This is distinct from the symbolic capital, in its various forms, that individuals may possess (Bourdieu 1989). Their ability to perform well in front of a camera or the quality and quantity of their connections with journalists can be imagined as 'a new form of capital' that is convertible 'across social space as a whole' (Couldry 2003: 670). Here, we are helped by Philip Schlesinger's attentiveness to source strategies. Schlesinger, also working with Bourdieu's field theory, identifies media coverage as an 'achievement' for sources, accomplished through their strategic engagement with journalists and media processes (Schlesinger 1990: 79). Resources, or capital, are unequally distributed - Schlesinger notes that journalism favours official sources - but all parties can work to secure prestige available through media coverage. This symbolic capital plays within the specific fields in which these individuals operate, though it is given worth by the downward pressure of media's meta-capital. We see this at work in the sample of Muslim sources discussed here. I classify the responses for participants into four categories of what I consider beneficiaries of media engagement: self, community, journalist, and society as a whole.

\section{Self, community, journalists, society}

It can be personally beneficial to engage with the media. To be seen in the media speaking about things confers a kind of symbolic capital can legitimate a source, conferring the status of an 'authorised knower' (Munnik 2017a). This can help the source manage relations within Muslim groups and communities and externally, with other niche groups or with society as a whole. It can be seen as a bit crass, or at least self-aggrandising: few participants dwelt on the personal benefits of being a source during our interviews. Nonetheless, Aamer Anwar, who is a lawyer and campaigner, spoke of being 'probably the lawyer with the highest profile in the city.' He accrued that profile by diligently sending out press releases on cases and campaigns, speaking with fiery soundbites that appeal to journalists, and getting to know their needs, rhythms, and priorities. The capital he accrued has opened new opportunities - for 
three years, he had a weekly column in a popular Sunday tabloid - and enhanced his performance in his established professional role.

As an example, Anwar was, at the time of our interview, representing the family of a Glasgow woman who had been murdered on a visit to Pakistan. He had learned that the Pakistani investigators had named a suspect, and he used his knowledge of media routines and his influence with news workers to get that story out and further his case. This feat was accomplished through a combination of his status as a lawyer (legal concerns were behind the editors' reticence to publish the story), his enduring relationships with the journalists (he used only the first names of editors and media lawyers as he related the story to me), and his awareness of the internal competitiveness of journalism: once he had convinced one broadcaster to interview the Pakistani official, he informed the other broadcaster, to pressure it to follow suit. He then let the Scottish press know that the story was going to air on the evening news so that they would include it in the next day's newspapers.

Personal gain can also be identified instrumentally, through the success of the organisation. Smina Akhtar, at the time the director of Amina, spoke of the benefit of getting her name and her organisation's name in media coverage: 'When you have a good public profile, and people know that you exist, then funders know you exist as well.' At a workshop, she learned from a representative of a funding agency that Amina's active media engagement had been noticed: "She said, "Yes, Smina, I've seen you on Newsnight," or, "I've heard you on the radio." [...] It does help.' Of my participants, Akhtar was one of the most ambivalent about the media, not only because of her perception of negativity but also uncertainty that she could control media interest to secure coverage when she needed it. Nonetheless, she described this direct benefit.

Akhtar's example bridges the gap between categories of 'self' and 'community'. She aligns her success with the work of the organisation. Of course, she benefits personally in that, by securing grants, she can continue in her role with Amina, thereby securing an occupation, influence, and an income. However, her role, and that of the centre she led, is oriented to serving women in Scotland, with a specific concentration on Muslim women. Strengthening such an organisation can benefit the wider community invoked by my participants. 'Community' is a notoriously difficult term (Baumann 1996; Williams 1988), sometimes concealing divisions behind a patina of unity or operating as code for minority concerns, be they ethnic, religious, or gender-based. My participants usually used the term in an uncritical fashion, referring to Muslims in an ummatic or global sense, Muslims in Glasgow, or Pakistani Muslims in Glasgow.

But the work of sources engaging with journalists has helped the community both now and in history. Bashir Maan, an elder among Glaswegian Muslims, became a middle-man or interlocutor between Pakistani immigrants and various civic institutions in the $1950 \mathrm{~s}$ and $60 \mathrm{~s}$. Initially, those were government services, but the range of institutions widened to include the press. With his language skills, education, and status in the community, he became a fixer for journalists curious about a community they could not access. That could involve benign, vaguely Orientalist profiles in the papers about 'the quiet strangers [who] work and pray' (Quigley 1958) or damage control in the face of stories about the so-called 'dodgy landlord' who gets criticised by a tenant in a tabloid piece. By negotiating relations between journalists and Muslims in his network, Maan helped manage and influence the publicity of Muslims in Glasgow. 
Considering more current media relations, several participants spoke to me about their desire to speak out after 9/11 (Munnik 2017b). Leaders in the community met about a fortnight after the attack, discussing how to respond in the face of a thickening anti-Muslim rhetoric. Although many of those elders advocated keeping their heads down, according to Osama Saeed, the younger ones felt that 'this had to be a moment where we seek to explain ourselves, we seek to build bridges between ourselves and other communities, and more than ever we need to speak.' Engaging with the media was pitched as a form of community defence.

Saeed's contemporary, Arifa Farooq, ended up working in broadcasting. Farooq is the participant who crosses the porous boundary between the categories of 'journalist' and 'source' - a Muslim working primarily in journalism in Glasgow. I include her comments here alongside sources, as she felt that her position gave her an opportunity to represent Muslims, in her view, more accurately than someone with no knowledge of or sympathy with that religious population. She joked about being 'the unofficial Muslim helpline' for colleagues, and from 9/11 on, she was asked by colleagues to provide contact details for potential Muslim sources and clarify ideas about Islam that they worried might be incorrect. In one instance, she appeared on a competitor's news broadcast as a panellist following strong global reactions to a YouTube programme about the prophet Muhammad; she was billed on the broadcast as a 'Muslim journalist' and given a representative role on behalf of 'the community.' By taking on these roles, the journalist risks being 'pigeon-holed' (Muir and Smith 2011: 233), which can have a limiting effect on her career. Farooq told me she did not mind being profiled at work: 'I would rather do it [the "Muslim" story] than you put someone else on it that has to maybe either start from scratch or get it completely wrong.' Muslims can suffer from misrepresentation, and as a Muslim, Farooq therefore has a stake in those consequences; as a journalist, she has an opportunity to intervene and perhaps avoid the consequences altogether.

Farooq's role as a journalist points to the third category of beneficiaries of media engagement: journalists themselves. Just as she and her fellow Muslims can be harmed by poor reporting, Farooq suggested that such reporting was harmful for the news organisation itself. The public nature of broadcasting, she said, meant 'you're kind of in the line of fire if you don't do your homework.' Accuracy is a core value of Western traditions of journalism (Shapiro et al. 2013). Farooq is therefore defending journalism practice and news institutions by insisting journalists cover Muslims accurately. She described apprehension among her colleagues that, as she said, 'drives me insane. "Is it okay to ask that question - I'm not going to offend someone?" No, it's - it's - as a journalist, you need to ask those questions. You need to get it right.' (emphasis Farooq) She engages with them as a colleague and as a Muslim to help them improve their own reporting.

Though he worked for broadcaster Al Jazeera in Doha at the time of our interview, Saeed was typically a source in Glasgow. He joked that he had become something of a 'Rent-a-quote' ${ }^{3}$ because of his willingness to comment. This, too, had self-oriented benefits that we can read into his trajectory, though he did not discuss them with me. He did speak of an orientation to service: 'the approach that I took with this stuff was to be as helpful as possible.' In contrast to the view he imputed to many Muslims in Scotland, as recorded at the beginning of this article, he believed that much of the

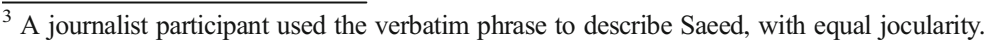


negativity expressed in the media was a result of ignorance rather than malice: 'newsrooms were overwhelmingly white and overwhelmingly didn't have- [or had] very few if any Muslims working within there.' This lack of contact would lead to 'misconceptions', he said, so it was incumbent upon him to contribute to coverage.

Samina Ansari, the campaign manager with Amina who generated a high spike in coverage for the organisation in 2012, also spoke of benefiting journalists through her engagement. Her qualities make it easy to see why journalists would favour speaking with her: at a practical level, she speaks in stories rather than abstract concepts, making her statements image-rich and easy for journalists to use. Moreover, Ansari is expressive and energetic, with a thick west-Scotland brogue; she wears a hijab and has brown skin and a markedly Asian name. These seeming contradictions symbolise the 'civic' rather than 'ethnic' nationalism Scotland's political leaders have been crafting (Meer 2015), for although she does not look at first glance like the stereotypical Scot, her accent locates her firmly in the Scottish nation (Virdee et al. 2006; cf. Kiely et al. 2001).

Despite her lack of journalistic experience, Ansari was sympathetic to journalists, articulating the pressure they faced to have someone who could speak on the record. Journalists sometimes need sources in a hurry to meet deadlines, and this was difficult for Amina staff, who wanted to consider their response before being quoted. In these situations, Ansari would advocate for a quick response, but by the time the centre had a statement prepared, she said, 'it [would] be too late.' Ansari struggled with these conflicting priorities: she understood the reasons for the centre's cautious approach; however, she had experienced the benefit to her campaign from heightened media exposure. Her publicity of the I Speak for Myself campaign had been positive, and she wanted to build on the relationships she had struck with journalists and organisations. She knew how important it was to be called back by journalists, and so she attempted either to respond herself or ensure someone else from the organisation could speak. When someone from Amina was invited to comment, Ansari said, her group was 'being thrown a line. Like, let's take the opportunity. So they're not going to contact us, ehm, unless, you know, they think...' Ansari tailed off her answer, but the implication is that if Amina could not say 'yes' and help with the journalists' requests, journalists would call less often or not at all. The benefit of engagement is reciprocal, in the sense that nurturing the relationship with journalists means that relationship continues.

Throughout my interview with Ansari, it was apparent that her orientation was generally towards service. Through her campaigning work, she sought to benefit her organisation, Muslim women in Scotland, and the journalists she encountered, but also Scottish society as a whole. Ansari said the issues that Amina cultivated expertise in, such as violence against women, educational attainment for children, and social marginalisation in terms of employment, had a broader impact: Amina's advocacy 'would benefit all people from all communities.' Her broad point was that Muslim women in Scotland are part of Scotland, and their concerns match with Scottish concerns. Thus, her persistence in media engagement benefited society.

Her colleague, Fariha Thomas, a board member with Amina and a city councillor in Glasgow, echoed that sentiment and broadened it beyond Scotland's borders. Thomas is part of the Muslim Women's Network UK, and she discussed a study the network had prepared on the vulnerability of Asian girls to sexual blackmailing. The study did not limit itself to the ethnic dimensions of the issue, and the network was linked with other agencies in the wider voluntary sector, the staff and researchers of which 'were 
able to say, "Yes, this is absolutely the case." Because then it's not just that wee bunch of women, it's a broader issue.' Thomas's statement reveals the layers of marginalisation her cohort face, implicating religion, gender, ethnicity, and location relative to the economic and political centre of Britain - namely, London and the southeast; alternately, it shows the intersectional work of overcoming those marginalisations (Mirza 2013; Samad 1998). The media relations of the Muslim Women's Network UK thus transcend the particularities for which 'community' has become a code.

\section{Conclusion}

As I stated at the beginning of this article, there is no requirement to talk to journalists. Sometimes, they can be aggressive, insensitive, and invasive with their questions. Often, they contact individuals or organisations because something has gone wrong, and for Muslims in Britain, that is more likely to be the case than for other groups. There are consequences for those who appear in the news - the individuals or groups directly involved, and in some cases the wider population that is associated with them. This is an element of the discussion concerning Islamophobia, in which all of those who identify or are identified as Muslim bear the brunt of social hostility. It would be understandable for a Muslim in Britain to withdraw from any invitation to engage with journalists.

Yet Muslims do engage with journalists, acting as sources and providing comment, background knowledge, and even the initial tip that starts a news story's progress to publication. They may do this out of a feeling of compulsion: Couldry's media metacapital identifies a symbolic power the media possess to impose their priorities on other fields. The ubiquity and social force of the media make them hard to resist. This does not mean citizens are utterly beholden to the news media. Journalists are heteronomous: as the literature on their relations reveals, journalists rely on sources in order to do their jobs. They cannot fill their pages, screens, or airwaves without the direct and indirect contributions of others. Here, we see the utility of Schlesinger's consideration of source strategies: they manage their engagement with the media and contribute to the creation of news content.

The Muslim sources I spoke to in my study had little that was good to say about journalism and journalists. They characterised the field as inaccurate, sensationalistic, or even sinister. The most common conception was of negativity: these were either direct or refracted statements. Positive conceptions, to the extent that they emerged at all, highlighted a difference in Scottish media as compared with UK media or an improvement from how the media used to be. These statements may be cold comfort: if relations are good in Scotland, it is little help for people who are at the same time resident in, under the authority of, and subjected to media messages from a wider Britain that, in their view, remains less satisfactory. If relations are better now, it implies a time when relations were worse.

These findings are consistent with other social research on the attitudes of Muslims in Britain, but they have an added power as commentary on the news media. Though this paper is based on impressions of journalism from non-journalists, it is not a random sample drawn from the population at large, nor is it a representative sample of Muslims in Glasgow. It is a purposive sample of Muslims engaged in the production of news about Muslims through their relations with journalists as news sources. Despite their 
dismal conceptions of the field, it is a field they persist in engaging with. Their strategic choices address the question of why they bother speaking with journalists. They perceive a range of beneficiaries, spreading out in concentric circles of concern. The sources themselves benefit, as the symbolic capital that accrues from being seen in the media and having connections in journalism can help them with their goals. The putative community of Muslims can benefit, as sources combat negative coverage with alternative narratives in a form of cultural defence. Journalists themselves benefit by fulfilling their professional roles, and some sources in my sample were sympathetic to those needs. By helping journalists improve the coverage of Muslims, some sources suggested they were improving the quality of information available to everyone, benefitting society and expanding community from a nucleus of fellow Muslims in Glasgow to a wider public.

Scotland is a unique site within Britain, Europe, and the West. Further study on the relational dynamics between Muslim sources and the mainstream media in different national contexts will help us understand both their perceptions of journalism and their motivations for contributing to it. Their participation, in the face of vilification, may reveal the ways they believe they can change social narratives about Muslims, as well as the possible limits to that change. It may also help us better understand the pervasive power of the news media as a social institution, setting the conditions in which certain kinds of citizens and groups can participate and be known in society.

Acknowledgements The author received a doctoral scholarship from the Alwaleed Centre for the Study of Islam in the Contemporary World, University of Edinburgh, to support the research in this article. Parts of this article were previously given as presentations at Muslims in Britain Research Network, Coventry University, 5 April 2016 and International Association for Media and Communication Research, University of Leicester, 27-31 July 2016.

\section{Compliance with ethical standards}

Conflict of interest The author declares no conflict of interest.

Informed consent Participants in this study took part with informed consent. They were provided with an information sheet concerning the project and completed a consent form, indicating their awareness of the project and their right to withdraw, their consent to being recorded, and their choice to be identified or kept anonymous. Most participants consented to being identified, and their names are used in the paper. Those who chose to retain anonymity are not named but instead loosely described in the text.

Open Access This article is distributed under the terms of the Creative Commons Attribution 4.0 International License (http://creativecommons.org/licenses/by/4.0/), which permits unrestricted use, distribution, and reproduction in any medium, provided you give appropriate credit to the original author(s) and the source, provide a link to the Creative Commons license, and indicate if changes were made.

\section{References}

Al-Azami, S. (2016). Religion in the media: A linguistic analysis. London: Palgrave Macmillan.

Alderman, J., \& Mast, N. (2017). When discussing Trump's Muslim ban, cable news excluded Muslims. Media Matters. https://mediamatters.org/blog/2017/02/09/when-discussing-trumps-muslim-ban-cablenews-excluded-muslims/215284. Accessed 10 Feb 2017. 
Ali, S. (2008). Second and third generation Muslims in Britain: A socially excluded group? Identities, integration and community cohesion. In Presented at the 12th annual Aage Sorensen memorial conference. Cambridge: Mass http://www.wjh.harvard.edu/ hos/papers/Sundas\%20Ali.pdf. Accessed 30 March 2011.

Baker, P., Gabrielatos, C., \& McEnery, T. (2013). Discourse analysis and media attitudes: The representation of Islam in the British press. Cambridge: Cambridge University Press.

Baumann, G. (1996). Contesting culture: Discourses of identity in multi-ethnic London. Cambridge: Cambridge University Press.

Bleich, E., Stonebraker, H., Nisar, H., \& Abdelhamid, R. (2015). Media portrayals of minorities: Muslims in British newspaper headlines, 2001-2012. Journal of Ethnic and Migration Studies, 41(6), 942-962.

Bonino, S. (2016). Muslims in Scotland: The making of community in a post-9/11 world. Edinburgh: Edinburgh University Press.

Bourdieu, P. (1989). Social space and symbolic power. Sociological Theory, 7(1), 14-25.

Carlson, M. (2009). Dueling, dancing, or dominating? Journalists and their sources. Sociology Compass, 3(4), 526-542.

Castells, M. (1997). The power of identity: The information age: Economy, society and culture, volume II. Oxford: Blackwell.

Commission on British Muslims and Islamophobia. (1997). Islamophobia: A challenge for us all. In London: Runnymede Trust.

Couldry, N. (2003). Media meta-capital: Extending the range of Bourdieu's field theory. Theory and Society, $32(5 / 6), 653-677$.

de Rooij, L. (2017). Believing and belonging: The aesthetics of media representations of Islam and Muslims in Britain and its relationship to British civil religion. Journal of Religion in Europe, 10(1-2), 172-217.

DeHanas, D. N., \& Pieri, Z. P. (2011). Olympic proportions: The expanding scalar politics of the London 'Olympics mega-mosque' controversy. Sociology, 45(5), 798-814.

Ericson, R. V., Baranek, P. M., \& Chan, J. B. L. (1989). Negotiating control: A study of news sources. Milton Keynes: Open University Press.

Gans, H. J. (1980). Deciding what's news: A study of 'CBS evening news', 'NBC nightly news', 'Newsweek', and 'time. New York: Vintage Books.

Hopkins, P. (Ed.). (2017). Scotland's Muslims: Society, politics and identity. Edinburgh: Edinburgh University Press.

Hussain, A., \& Miller, W. (2006). Multicultural nationalism: Islamophobia, Anglophobia, and devolution. Oxford: Oxford University Press.

Jaspal, R., \& Cinnirella, M. (2010). Media representations of British Muslims and hybridised threats to identity. Contemporary Islam, 4(3), 289-310.

Kabir, N. (2010). Young British Muslims: Identity, culture, politics and the media. Edinburgh: Edinburgh University Press.

Kiely, R., Bechhofer, F., Stewart, R., \& McCrone, D. (2001). The markers and rules of Scottish national identity. The Sociological Review, 49(1), 33-55.

Manning, P. (2001). News and news sources: A critical introduction. London: Sage.

MediaWise. (n.d.). Coping with media interest after a trial. MediaWise. http://www.mediawise.org.uk/wpcontent/uploads/2011/03/Coping-after-a-trial.pdf. Accessed 13 June 2016.

Meer, N. (2012). Misrecognizing Muslim consciousness in Europe. Ethnicities, 12(2), 178-196.

Meer, N. (2015). Looking up in Scotland? Multinationalism, multiculturalism and political elites. Ethnic and Racial Studies, 38(9), 1477-1496.

Meer, N., \& Modood, T. (2009). Refutations of racism in the 'Muslim question'. Patterns of Prejudice, 43(34), 335-354.

Miles, R., \& Dunlop, A. (1986). The racialization of politics in Britain: Why Scotland is different. Patterns of Prejudice, 20(1), 23-33.

Miller, D., Kitzinger, J., Williams, K., \& Beharrell, P. (1998). The circuit of mass communication: Media strategies, representation and audience reception in the AIDS crisis. London: Sage.

Mirza, H. S. (2013). A second skin': Embodied intersectionality, transnationalism and narratives of identity and belonging among Muslim women in Britain. Women's Studies International Forum, 36(1), 5-15.

Moore, K., Mason, P., \& Lewis, J. (2008). Images of Islam in the UK: The representation of British Muslims in the national print media 2000-2008. Cardiff: Cardiff School of Journalism, Media and Cultural Studies http://www.cardiff.ac.uk/jomec/resources/08channel4-dispatches.pdf. Accessed 2 May 2011.

Muir, H., \& Smith, L. (2011). Keeping your integrity - and your job: Voices from the newsroom. In J. Petley \& R. Richardson (Eds.), Pointing the finger: Islam and Muslims in the British media (pp. 221-249). Oxford: Oneworld. 
Munnik, M. B. (2017a). A field theory perspective on journalist-source relationships: A study of 'new entrants' and 'authorised knowers' among Scottish Muslims. Sociology. https://doi.org/10.1177 /0038038517696220.

Munnik, M. B. (2017b). From 'voice' to ‘voices': Identifying a plurality of Muslim sources in the news media. Media, Culture \& Society, 39(2), 270-281.

Poole, E. (2002). Reporting Islam: Media representations of British Muslims. London: I. B. Tauris.

Quigley, J. (1958). The quiet strangers work and pray. Scottish Sunday Express.

Richardson, J. E. (2004). (Mis)representing Islam: The racism and rhetoric of the British broadsheet newspapers. Amsterdam: John Benjamins.

Richardson, J. E. (2006). Who gets to speak? A study of sources in the broadsheet press. In E. Poole \& J. E. Richardson (Eds.), Muslims and the news media (pp. 103-115). London: I.B. Tauris.

Said, E. W. (1997). Covering Islam: How the media and the experts determine how we see the rest of the world (Rev. ed.). London: Vintage.

Samad, Y. (1998). Media and Muslim identity: Intersections of generation and gender. Innovation: The European Journal of Social Science Research, 11(4), 425-438.

Schlesinger, P. (1990). Rethinking the sociology of journalism: Source strategies and the limits of mediacentrism. In M. Ferguson (Ed.), Public communication: The new imperatives: Future directions for media research (pp. 61-83). London: Sage.

Shapiro, I., Brin, C., Bédard-Brûlé, I., \& Mychajlowycz, K. (2013). Verification as a strategic ritual. Journalism Practice, 7(6), 1-17.

Silk, M. (1998). Unsecular media: Making news of religion in America. Urbana: University of Illinois Press.

Thompson, J. B. (1988). Mass communication and modern culture: Contribution to a critical theory of ideology. Sociology, 22(3), 359-383.

Tunstall, J. (1971). Journalists at work: Specialist correspondents: Their news organizations, news sources, and competitor-colleagues. London: Constable.

Virdee, S., Kyriakides, C., \& Modood, T. (2006). Codes of cultural belonging: Racialised national identities in a multi-ethnic Scottish neighbourhood. Sociological Research Online, 11(4) http://www.socresonline.org. uk/11/4/virdee.html. Accessed 8 March 2013.

Williams, R. (1988). Keywords: A vocabulary of culture and society (2nd ed.). London: Fontana.

Willemse, K., \& Bergh, S. I. (2016). Struggles over access to the Muslim public sphere: Multiple publics and discourses on agency, belonging and citizenship. Contemporary Islam, 10(3), 297-309. 